\title{
NDV-induced apoptosis in absence of Bax; evidence of involvement of apoptotic proteins upstream of mitochondria
}

\author{
Aidin Molouki ${ }^{1}$ and Khatijah Yusoff ${ }^{1,2^{*}}$
}

\begin{abstract}
Background: Recently it was shown that following infection of HeLa cells with Newcastle disease virus (NDV), the matrix (M) protein binds to Bax and subsequently the intrinsic pathway of apoptosis is activated. Moreover, there was very little alteration on mRNA and protein levels of Bax and Bcl-2 after infection with NDV.

Finding: In order to further investigate the role of members of the Bcl-2 family, Bax-knockout and wild-type HCT116 cells were infected with NDV strain AF2240. Although both cells underwent apoptosis through the activation of the intrinsic pathway and the release of cytochrome $\mathrm{c}$ from mitochondria, the percentage of dead Bax-knockout cells was significantly lower than wt cells (more than $10 \%$ at $48 \mathrm{~h}$ post-infection). In a parallel experiment, the effect of NDV on HT29 cells, that are originally Bcl-2-free, was studied. Apoptosis in HT29 cells was associated with Bax redistribution from cytoplasm to mitochondria, similar to that of HeLa and wt HCT116 cells.

Conclusion: Although the presence of Bax during NDV-induced apoptosis contributes to a faster cell death, it was concluded that other apoptotic protein(s) upstream of mitochondria are also involved since cancer cells die whether in the presence or absence of Bax. Therefore, the classic Bax/Bcl-2 ratio may not be a major determinant in NDV-induced apoptosis.
\end{abstract}

\section{Findings}

Newcastle disease virus (NDV) is a highly contagious avian virus that belongs to the genus Avulavirus from the family of Paramyxoviridae [1,2]. NDV is mostly recognized for its economic damage to the poultry industry worldwide since it causes high mortality rates in most species of bird [3,4]. NDV strains are mainly grouped into three major pathotypes on the basis of their pathogenicity $[5,6]$, where lentogenic strains cause clinically low or unapparent respiratory disease, mesogenic strains cause intermediate symptoms and have moderate mortality rate, and lastly velogenic strains that cause severe intestinal lesions and neurological effects with high mortality rates. Malaysian NDV strain AF2240 is a viscerotropic velogenic strain that was isolated during an outbreak in the country in the 1960s and it is

\footnotetext{
* Correspondence: kyusoff@biotech.upm.edu.my

${ }^{1}$ Institute of Biosciences, Universiti Putra Malaysia, 43400 UPM, Serdang, Selangor DE, Malaysia

${ }^{2}$ Department of Microbiology, Faculty of Biotechnology and Biomolecular Sciences, Universiti Putra Malaysia, 43400 UPM, Serdang, Selangor DE, Malaysia
}

now mostly used as the challenge virus in vaccine trials in Malaysia [7]. On the other hand, NDV has also gained a lot of interest in cancer virotherapy since it can selectively kill human cancer cells [5]. It has been shown that NDV induces apoptosis in cancer cells by activating the mitochondrial pathway $[8,9]$. The proteins of the $\mathrm{Bcl}-2$ family are known central regulators of this pathway [10]. Bcl-2 protein itself acts as pro-survival factor while proapoptotic members such as Bax initiate apoptosis [11]. All members of the Bcl-2 family interact with each other or other proteins via their conserved domains known as the Bcl-2 homology (BH) domains 1 to 4 [12]. Bcl-2, Bcl-XL, Bax, Bak, Bid and Bad are known members to regulate the mitochondrial membrane permeability transition pores (MPTP) [13-16] to act as checkpoints of apoptosis. We recently showed that the matrix (M) protein of NDV directly interacts with human Bax protein in HeLa cells through its BH3 domain [17]. This interaction activates Bax and subsequently initiates the release of cytochrome $\mathrm{c}$ from mitochondria to further activate the intrinsic pathway. Activation of some

\section{Biomed Central}


caspases such as caspase- 3 in several cell lines following NDV infection has been frequently reported as well [8,18-20].

\section{Bax-knockout cells are more resistant to NDV infection} In the current study, the effect of NDV on cancer cells in the absence of Bcl-2 and Bax was investigated; HT29 human colon adenocarcinoma cell line (originally Bcl-2free, purchased from ATCC), HCT116 Bax-/- (kindly provided by Bert Vogelstein, Johns Hopkins Medical University, MD, USA) and wt colorectal carcinoma cell lines (kindly provided by Eric Stanbridge, University of California, Irvine, CA, USA) were cultured in 6-well plates and infected with NDV strain AF2240 according to a standard protocol (30 HA units of NDV for $1.0 \times$ $10^{6}$ cultured cells) [21]. Bax-deficient HCT116 cells were generated by targeted inactivation of the wild-type Bax allele in a Bax heterozygote [22].

Morphological changes and membrane blebbing was completely evident in these cell lines following infection. At different time points post-infection $(18 \mathrm{~h}, 36 \mathrm{~h}$ and $48 \mathrm{~h}$ ), the cells were checked by flowcytometry and PI staining for the number of dead cells, and graphs were drawn accordingly (Figure 1). At $48 \mathrm{~h}$ post-infection $75.76 \%$ of HT29 cells, $68.71 \%$ of wt HCT116 cells and only $58.09 \%$ of HCT116 Bax-/- cells were stained positive. The difference between the percentages of dead cells in HCT116 Bax-/- cell line compared to wt HCT116 was statistically significant.

\section{Translocation of Bax from cytoplasm to mitochondria}

Later, cytosolic and mitochondrial fractions of the NDVinfected cells were collected as previously described [9] and the samples were subjected to SDS-PAGE and Western blotting with anti-Bax clone 2D2 antibody (Zymed, USA) (Figure 2). HT29 and wt HCT116 cell lines showed that following NDV infection the amount of Bax increased in the mitochondrial fraction (not shown) while Bax became less detectable in the cytosolic fraction. Absence of Bax in knockout HCT116 cells was also checked.

\section{Activation of intrinsic pathway in NDV-infected Bax- knockout cells}

Moreover, in order to investigate if the intrinsic pathway in the NDV-infected cells is activated, the ability of these cells to release cytochrome $\mathrm{c}$ from the mitochondria was also examined by subjecting the cytosolic fractions to Western blotting with anti-cytochrome c clone 7H8 antibody (Biovision, USA) (Figure 2). Similar to what was previously reported for HeLa cells [9], translocation of Bax from the cytosol into the mitochondria in NDV-

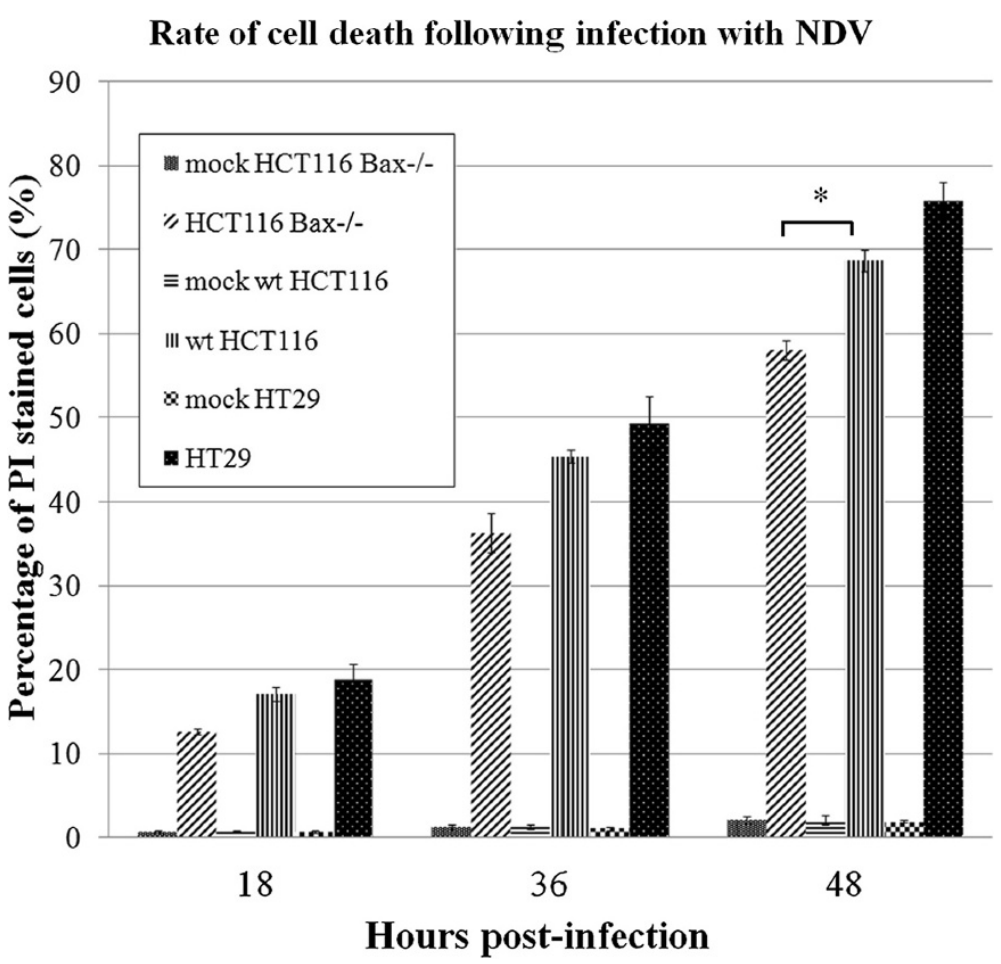

Figure 1 Comparison of the percentage of PI stained NDV-infected cells. Data are obtained at different time points $18 \mathrm{~h}, 36 \mathrm{~h}$ and $48 \mathrm{~h}$ by flowcytometry. Error bars indicate standard error of the mean from three independent measurements. The difference in the percentage of cell death in HCT116 Bax-/- cells compared to wt HCT116 at 48 h post-infection was statistically significant. *, $\mathrm{p}<0.05$. 


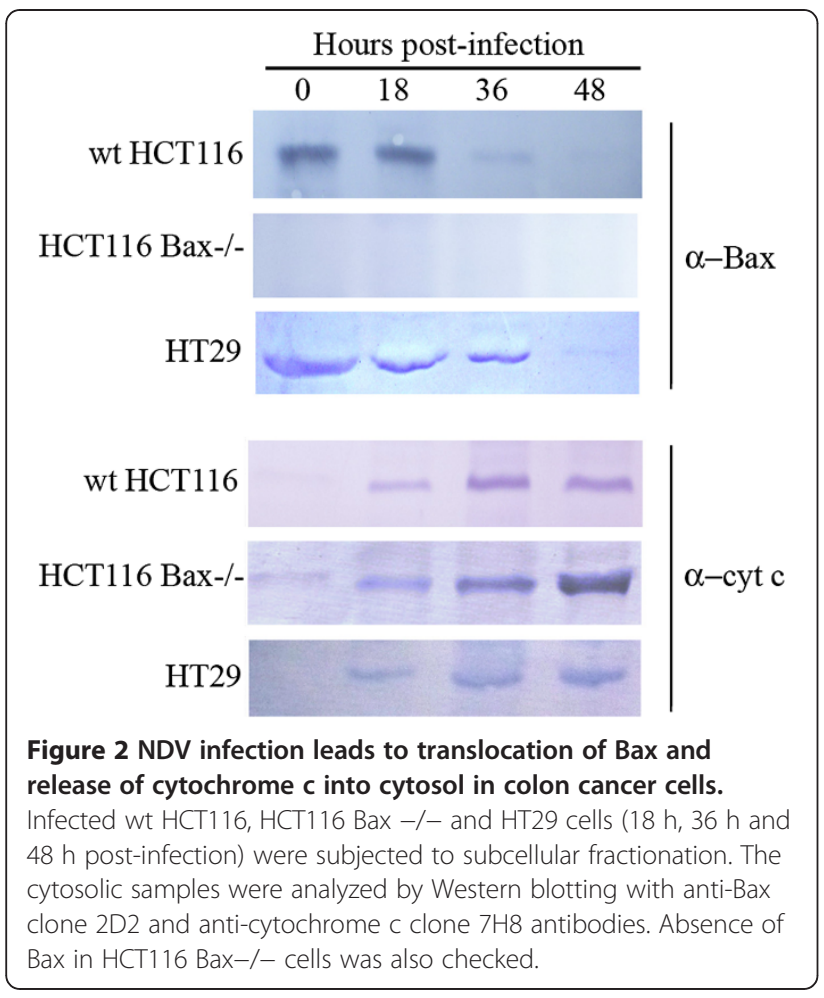

infected HT29 and wt HCT116 cell lines was followed by the release of cytochrome $\mathrm{c}$ from mitochondria into the cytosol.

In addition, the amount of cytochrome $\mathrm{c}$ in the cytosolic fraction of the NDV-infected HCT116 Bax-/- cells also increased by time, suggesting that the mitochondrial pathway of apoptosis in this cell line is activated even in the absence of Bax.

\section{Discussion}

In this study, after several trials, it was found that the percentage of cell death in NDV-infected Bax-knockout cells was lower compared to wt cells. This showed that the presence of Bax (and its subsequent interaction with the viral proteins such as the $M$ protein) speeds up the apoptosis event. Since the Bax-knockout cells die following infection with the virus, it can be concluded that NDV is able to interact with apoptotic proteins other than Bax as well. The release of cytochrome c into cytosol proves that the mitochondrial pathway is activated through some other interaction(s) that directly or indirectly affected the proteins of the surface of mitochondria, allowing formation of pores that release mitochondrial factors.

Many Bcl-2 family members interact with each other via the $\mathrm{BH}$ domains [12]. For instance, Bax binds to several of these proteins by its $\mathrm{BH} 3$ domain $[23,24]$ resulting in a series of complex interactions. Since the M protein of NDV contains a $\mathrm{BH} 3$ domain that interacts with Bax, it could be possible that in the absence of Bax, the $\mathrm{M}$ protein activates other pro-apoptotic members. However, so far this viral protein has shown no interaction with Bad, Bcl-XL and BimL [17]. Fusion (F) protein also failed to interact with the mentioned $\mathrm{Bcl}-2$ members. Moreover, the BH3-like regions on the large (L) protein of NDV have not yet been examined for their ability to bind to Bcl-2 family proteins.

Bcl-2 normally blocks Bax oligomerization to inhibit its insertion into the mitochondria [10]. Since NDV infection also leads to apoptosis in absence of Bax, the classic Bax/Bcl-2 ratio [10-12] may not be a major determinant in NDV-induced apoptosis. This statement is in agreement with our previous findings that there was very little alteration on mRNA and protein levels of Bax and Bcl-2 following infection with NDV [9,17]. Moreover, little is known about the role of anti-apoptotic members of the Bcl-2 family during NDV infection. Since HT29 cells are $\mathrm{Bcl}$-2-free, it will be interesting to check if the absence of $\mathrm{Bcl}-2$ has a significant role in NDV-induced apoptosis at all, or its overexpression has any effect on the apoptosis rate.

Bak and Bax have almost the same protein structure, share similar $\mathrm{BH}$ domains and are the only two proapoptotic Bcl-2 family proteins discovered so far that form oligomeric pores on the mitochondria surface. Bak can independently release cytochrome $\mathrm{c}$ from mitochondria in absence of Bax [25], and therefore these characteristics make it an excellent candidate for future studies. Although Bax is a cytosolic protein and Bak localizes to mitochondria, they both facilitate the release of cytochrome $\mathrm{c}$ from mitochondria through MPTP pores $[13,26]$.

BH3-only members such as Bid and Bad are located upstream of mitochondria that upon activation move towards mitochondria to, respectively, activate Bak and Bax [16] and inhibit Bcl-2 and Bcl-XL function [15] to facilitate release of mitochondrial factors. Therefore, if NDV proteins directly or indirectly (through activation of BH3-only protein) activate Bak in HCT116 Bax-/cells then perhaps this could be a possible reason behind the release of cytochrome c. Use of Bak-/- cells in future studies will definitely let us investigate this hypothesis further. On the other hand, it has been previously shown that NDV kills Bcl-XL-overexpressing cells that are resistant to Bak overexpression [27] and also overcomes the anti-apoptotic function of Livin [28], a novel member of the inhibitor of apoptosis protein (IAP) family frequently overexpressed in melanoma. Moreover, it has been found that during infection with RNA viruses a BH3-like domain of IRF-3 mediates binding to cytosolic Bax (but not Bcl-2, Bcl-XL or Bak) to induce Bax activation, culminating in cytochrome $\mathrm{c}$ release and apoptosome formation [29]. Together it could be further 
suggested that proteins located upstream of mitochondria are strong candidates for such activities.

Overall, it was concluded that Bax is not the only cellular protein that NDV proteins interact with to trigger apoptosis. However, Bax plays a role in the apoptosis of HCT116 cells, since the lack of Bax contributes to slower cell death. This further suggested that the interaction between Bax and NDV proteins, such as that with the $M$ protein [17], is crucial and acts as determinant during NDV-induced apoptosis. Further study is needed to find other possible interactions between NDV proteins and cellular apoptotic proteins.

\section{Abbreviations}

ATCC: American type culture collection; BH domain: Bcl-2 homology domain; wt: Wild-type.

\section{Competing interests}

The authors declare that they have no competing interests.

\section{Authors' contributions}

AM designed and performed the experiments and drafted the manuscript. KY participated in the design of the study, financial support and contributed to writing the manuscript. Both authors have read and approved the final manuscript.

\section{Acknowledgement}

Molouki A was supported by a GRF scholarship, UPM. This research was supported by the Malaysian Genome Institute Grant MGI-NBD0017-2007. The authors would like to thank Bert Vogelstein for providing the knockout cell lines and Eric Stanbridge for the wt colorectal carcinoma cell lines.

Received: 8 February 2012 Accepted: 28 August 2012

Published: 30 August 2012

\section{References}

1. Mayo MA: Virus taxonomy - Houston 2002. Arch Virol 2002, 147:1071-1076

2. Mayo MA: A summary of taxonomic changes recently approved by ICTV Arch Virol 2002, 147:1655-1663.

3. Alexander DJ: Newcastle disease and other avian Paramyxoviridae infections. In Diseases of Poultry. 10th edition. Edited by Calnek BW. Ames: lowa State University Press; 1997:541-569.

4. Alexander DJ: Newcastle disease and other avian paramyxoviruses. In $A$ Laboratory Manual for the Isolation and Identification of Avian Pathogens. Edited by Purchase HG, Arp LH. Kennett Square: American Association of Avian Pathologists; 1998:156-163.

5. Yusoff $K$, Tan WS: Newcastle disease virus: macromolecules and opportunities. Avian Pathol 2001, 30:439-455.

6. Romer-Oberdorfer A, Werner O, Veits J, Mebatsion T, Mettenleiter TC Contribution of the length of the $\mathrm{HN}$ protein and the sequence of the $\mathrm{F}$ protein cleavage site to Newcastle disease virus pathogenicity. J Gen Virol 2003, 84:3121-3129.

7. Lai MC, Ibrahim AL: Velogenic viscerotropic Newcastle disease virus. In Newcastle disease in poultry: a new food pellet vaccine. Volume monograph 5. Edited by Copland JW. Canberra: ACIAR; 1987:33-34.

8. Elankumaran S, Rockemann D, Samal SK: Newcastle disease virus exerts oncolysis by both intrinsic and extrinsic caspase-dependent pathways of cell death. J Virol 2006, 80:7522-7534.

9. Molouki A, Hsu YT, Jahanshiri F, Rosli R, Yusoff K: Newcastle disease virus infection promotes Bax redistribution to mitochondria and cell death in HeLa cells. Intervirology 2010, 53:87-94.

10. Gross A, McDonnell JM, Korsmeyer SJ: BCL-2 family members and the mitochondria in apoptosis. Gene Dev 1999, 13:1899-1911.

11. Oltvai ZN, Milliman $\mathrm{CL}$, Korsmeyer SJ: $\mathrm{Bcl}-2$ heterodimerizes in vivo with a conserved homolog, Bax, that accelerates programmed cell death. Cell 1993, 74:609-619.
12. Willis $\mathrm{S}$, Day $\mathrm{CL}$, Hinds MG, Huang DC: The Bcl-2-regulated apoptotic pathway. J Cell Sci 2003, 116:4053-4056.

13. Shimizu S, Narita M, Tsujimoto Y: BCl-2 family proteins regulate the release of apoptogenic cytochrome $\mathrm{c}$ by the mitochondrial channel VDAC. Nature 1999, 399:483-487.

14. Sugiyama T, Shimizu S, Matsuoka Y, Yoneda Y, Tsujimoto Y: Activation of mitochondrial voltage-dependent anion channel by apro-apoptotic BH3-only protein Bim. Oncogene 2002, 21:4944-4956.

15. Yang E, Zha J, Jockel J, Boise LH, Thompson CB, Korsmeyer SJ: Bad, a heterodimeric partner for $\mathrm{BCl}-\mathrm{XL}$ and $\mathrm{BCl}-2$, displaces $\mathrm{Bax}$ and promotes cell death. Cell 1995, 80:285-291.

16. Korsmeyer SJ, Wei MC, Saito M, Weiler S, Oh KJ, Schlesinger PH: Proapoptotic cascade activates BID, which oligomerizes BAK or BAX into pores that result in the release of cytochrome c. Cell Death Differ 2000 7:1166-1173.

17. Molouki A, Hsu YT, Jahanshiri F, Abdullah S, Rosli R, Yusoff K: The matrix (M) protein of newcastle disease virus binds to human bax through its $\mathrm{BH} 3$ domain. Virol J 2011, 8:385.

18. Ravindra PV, Tiwari AK, Sharma B, Rajawat YS, Ratta B, Palia S, Sundaresan NR, Chaturvedi U, Kumar GB, Chindera K, et al: HN protein of Newcastle disease virus causes apoptosis in chicken embryo fibroblast cells. Arch Virol 2008, 153:749-754.

19. Kommers GD, King DJ, Seal BS, Carmichael KP, Brown CC: Pathogenesis of six pigeon-origin isolates of Newcastle disease virus for domestic chickens. Vet Pathol 2002, 39:353-362

20. Fabian Z, Csatary CM, Szeberenyi J, Csatary LK: p53-independent endoplasmic reticulum stress-mediated cytotoxicity of a Newcastle disease virus strain in tumor cell lines. Virology 2007, 81:2817-2830.

21. Schirrmacher V, Haas C, Bonifer R, Ahlert T, Gerhards R, Ertel C: Human tumor cell modification by virus infection: an efficient and safe way to produce cancer vaccine with pleiotropic immune stimulatory properties when using Newcastle disease virus. Gene Ther 1999, 6:63.

22. Zhang L, Yu J, Park BH, Kinzler KW, Vogelstein B: Role of BAX in the apoptotic response to anticancer agents. Science 2000, 290:989-992.

23. Zha H, Aime-Sempe C, Sato T, Reed JC: Proapoptotic protein Bax heterodimerizes with $\mathrm{BCl}-2$ and homodimerizes with $\mathrm{Bax}$ via a novel domain (BH3) distinct from $\mathrm{BH} 1$ and $\mathrm{BH} 2$. J Biol Chem 1996 , 271:7440-7444.

24. Zhou H, Hou Q, Chai Y, Hsu YT: Distinct domains of Bcl-XL are involved in Bax and Bad antagonism and in apoptosis inhibition. Exp Cell Res 2005, 309:316-328.

25. Degenhardt K, Sundararajan R, Lindsten T, Thompson C, White E: Bax and Bak independently promote cytochrome $\mathrm{c}$ release from mitochondria. J Biol Chem 2002, 277:14127-14134.

26. Waterhouse NJ, Ricci JE, Green DR: And all of a sudden it's over: mitochondrial outer-membrane permeabilization in apoptosis. Biochimie 2002, 84:113-121.

27. Mansour M, Palese P, Zamarin D: Oncolytic specificity of Newcastle disease virus is mediated by selectivity for apoptosis-resistant cells. J Virol 2011, 85:6015-6023.

28. Lazar I, Yaacov B, Shiloach T, Eliahoo E, Kadouri L, Lotem M, Perlman R, Zakay-Rones Z, Panet A, Ben-Yehuda D: The oncolytic activity of Newcastle disease virus NDV-HUJ on chemoresistant primary melanoma cells is dependent on the proapoptotic activity of the inhibitor of apoptosis protein Livin. Virology 2010, 84:639-646.

29. Vince JE, Tschopp J: IRF-3 partners Bax in a viral-induced dance macabre. EMBO J 2010, 29:1627-1628.

doi:10.1186/1743-422X-9-179

Cite this article as: Molouki and Yusoff: NDV-induced apoptosis in absence of Bax; evidence of involvement of apoptotic proteins upstream of mitochondria. Virology Journal 2012 9:179. 